\title{
Regularities and Systematic Trends on Zr IV Stark Widths
}

\author{
Zlatko Majlinger $^{1, \ddagger}$, Milan S. Dimitrijević ${ }^{1,2, *, t, \ddagger}{ }^{\mathbb{1}}$ and Zoran Simić ${ }^{1, \ddagger}$ \\ 1 Astronomical Observatory, Volgina 7, Belgrade 11060, Serbia; zlatko.majlinger@gmail.com (Z.M.); \\ zsimic@aob.rs (Z.S.) \\ 2 LERMA (Laboratoire d'Etudes du Rayonnement et de la Matière en Astrophysique et Atmosphères), \\ Observatoire de Paris, 5 Place Jules Janssen, 92195 Meudon CEDEX, France \\ * Correspondence: mdimitrijevic@aob.rs or milan.dimitrijevic@obspm.fr; Tel.: +381-64-297-8021 \\ + Current address: Astronomical Observatory, Volgina 7, Belgrade 11060, Serbia. \\ $\ddagger$ These authors contributed equally to this work.
}

Received: 10 September 2017; Accepted: 23 November 2017 ; Published: 1 December 2017

\begin{abstract}
Regularities and systematic trends among the Stark widths of $18 \mathrm{Zr}$ IV spectral lines obtained by modified semiempirical approach have been discussed. Also we compared those calculated Stark broadening parameters with estimates according to Cowley, Purić et al. and Purić and Śćepanović and checked the possibility to find some new estimates. It is demonstrated as well that the formula of Cowley (1971) overestimates Stark widths, obtained by using modified semiempirical method, with the increase of angular orbital momentum quantum number due to its neglection. It is also found that the results obtained by using formula for simple estimates of Purić et al. (1991) are in agreement with the modified semiempirical results within the estimated error bars of both methods, while the estimates using formula of Purić and Šćepanović (1999) are in strong disagreement which increases with the increase of angular orbital momentum quantum number.
\end{abstract}

Keywords: Stark broadening; line profiles; atomic data

\section{Introduction}

Stark broadening theory is very important for many laboratory and astrophysical plasma investigations, since the collisional processes between the charged particles contribute significantly to the spectral line broadening in high-temperature dense plasma. However, available numerous data on Stark widths of spectral lines are up to now still incomplete and despite of a great effort from different groups including French and Belgrade Schools and their co-workers (see e.g., [1-3] and references therein) in determination of Stark widths and shifts for spectral lines of many atoms and ions, the further work on the determination of missing Stark broadening data for applications in astrophysics and plasma physics is still needed.

When the required Stark broadening parameters are missing, and there is no data for the adequate use of more accurate theoretical methods, simple estimates seem very useful. Such quick estimates of Stark-broadening parameters may be based on different regularities and systematic trends among the Stark widths of atomic spectral lines (see e.g., [4]). We focus on present work on searching regularities and systematic trends of Stark widths for $18 \mathrm{Zr}$ IV spectral lines calculated in [5] by modified semiempirical approach (MSE_Dimitrijević \& Konjević [6]). This study has two directions. In the first, we compare existing calculated MSE results with estimates made in this work by formulae of Cowley [7], Purić et al. [8] and Purić \& Šćepanović [9]. In the second, we try to find estimates based on systematic trends among 18 calculated MSE results. We note as well that there is no experimental Stark broadening data in the literature. 


\section{Methods}

In all of our estimates in this work, the condition that temperatures are near threshold for collisional excitation or below, when Gaunt factor is constant, is satisfied.

$$
3 k T / 2\left|E_{j}-E_{j^{\prime}}\right|<2
$$

where $k$ is Boltzmann constant and $j^{\prime}$ is the perturbing level closest to initial or final level. In such a case, from MSE and the semiempirical method follows (see for further details Dimitrijević \& Konjević [6] and Griem [10]) that the dependence of Stark broadening parameters with temperature is

$$
f(T)=T^{-1 / 2} \text {. }
$$

For Zr IV lines considered in this work, the condition (1) is in most cases satisfied up to around $20,000 \mathrm{~K}$, for some cases even $30,000 \mathrm{~K}$, so that for all our analysed widths calculated for temperature $T=10,000 \mathrm{~K}$, the condition (1) is satisfied.

Estimation methods used in present research can be divided into two groups: (a) estimates derived from theory (b) estimates based on purely statistical analysis of existing data. We search the estimation formula in two versions. First, in dependence on effective ionization potential:

$$
\mathrm{W}_{E_{1}}=a_{1} Z^{c_{1}} \lambda^{2} N f(T)\left(E_{i o n}-E_{j}\right)^{-b_{1}}
$$

Second, in dependence on effective quantum number:

$$
\mathrm{W}_{E_{2}}=a_{2} Z^{c_{2}} \lambda^{2} N f(T)\left(n_{j}^{*}\right)^{-b_{2}}
$$

The relation between effective principal quantum number and upper or lower state is given by:

$$
n_{j}^{* 2}=Z^{2}\left[E_{H} /\left(E_{i o n}-E_{j}\right)\right]
$$

where $Z-1$ is ionic charge, $n^{*}$-effective principal quantum number, $W_{E}$ estimated Stark width in $\AA, \lambda$ wavelength in $\AA, N$-perturber density in $\mathrm{m}^{-3}, T$ temperature in $\mathrm{K}, E_{H}$-hydrogen atom energy, $E_{i o n}$-ionization energy, $E_{j}$-energy of upper ( $j=$ upper) and lower $(j=$ lower) level. Coefficients $a$, $b$ and $c$ in Equations (3) and (4) are independent of temperature, ionization potential and electron density for a given transition.

First we will estimate Stark widths with the simple formula of Cowley [7] which is often in use by some modern authors in original or modified form (see, for example, Killian et al. [11], Ziegler et al. [12] and Przybilla et al. [13]) and which has recently used by our team for comparison with MSE calculated values of Stark widths of Lu III spectral lines too, see Majlinger et al. [14]. In Majlinger et al. [5] we derived it from the Griem [10] semiempirical formula at low temperature limit and added the contribution to the width of the lower energy level. In such a case, the difference between original formula of Cowley and the modified formula in [5] is for a factor $2 / 3^{3 / 2}$ plus the contribution of the lower energy level. Here, we want to test the original formula of Cowley. After rearranging the original equation of Cowley [7] to express width in $\AA$, we obtain:

$$
\mathrm{W}_{\mathrm{Cow}}=\frac{h^{2}}{2 \pi c}\left(1 / 2 m^{3} \pi k\right)^{1 / 2} \frac{\lambda^{2} N}{Z^{2} \sqrt{T}}\left(n_{i}{ }^{* 4}\right)
$$

where $h$ is Planck's constant, $c$ speed of light and m mass of perturber.

The Cowley's formula is, as we can see, of the type of Equation (4), where $j=$ upper level, and parameters are $a_{2}=2.92 \times 10^{-30}, b_{2}=4$ and $c_{2}=-2$. 
Further, we test the possibility to use the statistical estimates of $[8,9]$ for quick prediction of unknown Stark widths. Comparing the great amount of Stark width data from STARK-B database [1,2], Purić and his co-workers found the correlation between Stark width and difference between ionization energy and energy of the upper state (which is, according to Purić, called upper effective ionization potential) and offered a set of different estimation formulae. Thus we compared our results from MSE calculations with two different approximations: so-called "generalized" estimate (Purić \& Šćepanović [9], in the rest of this text PS99) and estimate based on statistical regression analysis of multiply charged heavy ions (Purić et al. [8], in the rest of this text P91). All of Purić's formulae are of type of Equation (1). Purić's works are shown to be useful in some analysis and comparisons, and investigations of systematic trends and regularities, for example in the cases of searching the regularities and trends via specific homologous sequences $[15,16]$.

The equations for Stark width obtained from Purić's regression analysis of existing set of Stark broadening data was adapted for our purpose. After conversion of width from angular frequency units to Angstroms (see for example Hamdi [17]), coefficient values are recalculated from PS99 and P91, where these coefficients are given for Stark widths measured in $\mathrm{s}^{-1}$. Estimation formulae from PS99 and P91 finally is:

$$
\mathrm{W}_{\mathrm{PS} 99}=3.27 \times 10^{-28} Z^{5 / 2} \lambda^{2} N \sqrt{T}\left(E_{i o n}-E_{j}\right)^{-3.1}
$$

and

$$
\mathrm{W}_{\mathrm{P} 91}=2.52 \times 10^{-27} Z^{0} \lambda^{2} N \sqrt{T}\left(E_{i o n}-E_{j}\right)^{-1.73}
$$

respectively, if perturber density $N$ is expressed in $\mathrm{m}^{-3}$ and energies in $\mathrm{eV}$.

\section{Results and Discussion}

In Tables 1 and 2, calculated Stark widths of $18 \mathrm{Zr}$ IV lines made by different estimation methods mentioned above are compared to previous MSE calculations of Stark FWHM Majlinger et al. [5]. All results presented in Tables 1 and 2 are calculated for a temperature of 10,000 K and electron density of $10^{23} \mathrm{~m}^{-3}$. First we can see that widths $\mathrm{W}_{\mathrm{PS} 99}$ estimated according to Equation (7) are systematically higher than $W_{\text {COW }}$ done by Equation (6).

Second, we can see that $W_{\text {PS99 }}$ does not fit very well to WMSE widths, although this estimate should be generally applicable, the reasons for which we have already explained in detail in Majlinger et al. [5]. On the contrary, much better agreement is found between all of MSE results and results of estimate for multiple charged heavy ions obtained by Equation (8) in P91 (Equation (8) also in this paper), but only if dependence of estimate on residual charge $Z$ is neglected (e.g., parameters should be adopted to be $c=0$ or $Z=1$ ). In that case, the corresponding ratios of this comparison range from 0.4 to 2.2 .

In Table 3, we are presented ranges of values of ratios of $\mathrm{W}_{\mathrm{COW}}, \mathrm{W}_{\mathrm{PS} 99}$ and $\mathrm{W}_{\mathrm{P} 91}$ with $\mathrm{W}_{\mathrm{MSE}}$ for different types of transitions. As we can see, ratios between $W_{\text {COW }}$ and $W_{M S E}$ range from 0.8 to 4 , and they increase with the increase of the orbital angular momentum quantum number $\ell$, which is neglected in the Cowley's formula. For s-p transitions differences are from 0.82 up to 2.82 , for $p$-d from 1.57 up to 1.86 and for d-f from 3.74 up to 3.97. Consequently, obtained results demonstrate that for higher $\ell$ Cowley's formula overestimates the MSE values due to the neglection of $\ell$.

For the estimates $W_{\mathrm{PS} 99}$ the considered ratio for transitions of s-p type ranges from 1.40 to 8.34 while for other considered types of transitions this ratio is from 4.43 up to 24.27 . The ratio of $W_{\mathrm{P} 91}$ with $\mathrm{W}_{\text {MSE }}$ vary from 0.48 up to 2.13 which is acceptable for a rough estimate.

In articles of Cowley [7] and Purić \& Šćepanović [9] there is no discussion of the corresponding error bars. The assumed accuracy of MSE method is within the limits of $50 \%$ for simpler spectra while for complex spectra like for Zr IV might be worse. In Purić et al. [8] is stated that the agreement is within $40 \%$ error bars for the majority of cases. Consequently the ratio of $W_{P 91}$ with $W_{M S E}$ is within mutual error bars. 
Table 1. Estimated Stark widths for 18 spectral lines of Zr IV according to Cowley (1971) using Equation (6) $\left(\mathrm{W}_{\mathrm{COW}}\right)$ for a temperature of $\mathrm{T}=10,000 \mathrm{~K}$ and electron density of $\mathrm{N}=10^{23} \mathrm{~m}^{-3}$. Estimated Stark widths are compared with MSE calculated Stark widths $\mathrm{W}_{\text {MSE }}$ [5].

\begin{tabular}{|c|c|c|c|}
\hline Transition & $\lambda(\AA)$ & $\mathbf{W}_{\text {COW }}(\AA)$ & $\mathbf{W}_{\mathrm{COW}} / \mathbf{W}_{\mathrm{MSE}}$ \\
\hline $5 s^{2} S_{1 / 2}-5 p^{2} P_{1 / 2}^{o}$ & 2287.38 & 0.0768 & 0.91 \\
\hline $5 s^{2} S_{1 / 2}-5 p^{2} P_{3 / 2}^{0}$ & 2164.36 & 0.0706 & 0.92 \\
\hline $5 s^{2} S_{1 / 2}-6 p^{2} \mathrm{Po}_{1 / 2}^{0}$ & 760.16 & 0.0279 & 2.82 \\
\hline $5 s^{2} \mathrm{~S}_{1 / 2}-6 \mathrm{p}^{2} \mathrm{P}^{\mathrm{o}}{ }_{3 / 2}$ & 754.39 & 0.0280 & 2.75 \\
\hline $5 \mathrm{p}^{2} \mathrm{P}_{1 / 2}^{\mathrm{o}}-5 \mathrm{~d}^{2} \mathrm{D}_{3 / 2}$ & 1546.17 & 0.0784 & 1.86 \\
\hline $5 \mathrm{p}^{2} \mathrm{P}_{3 / 2}^{\mathrm{o}}-5 \mathrm{~d}^{2} \mathrm{D}_{3 / 2}$ & 1607.95 & 0.0847 & 1.81 \\
\hline $5 \mathrm{p}^{2} \mathrm{P}_{3 / 2}-5 \mathrm{~d}^{2} \mathrm{D}_{5 / 2}$ & 1598.95 & 0.0842 & 1.82 \\
\hline $5 d^{2} D_{3 / 2}-5 f^{2} F^{o}{ }_{5 / 2}$ & 1836.10 & 0.324 & 3.97 \\
\hline $5 d^{2} D_{5 / 2}-5 f^{2} \mathrm{~F}^{\mathrm{o}}{ }_{5 / 2}$ & 1848.03 & 0.328 & 3.97 \\
\hline $5 d^{2} D_{5 / 2}-5 f^{2} F^{o}{ }_{7 / 2}$ & 1846.37 & 0.328 & 3.97 \\
\hline $6 s^{2} S_{1 / 2}-6 p^{2} P^{o}{ }_{1 / 2}$ & 5781.45 & 1.62 & 0.82 \\
\hline $6 s^{2} S_{1 / 2}-6 p^{2} P_{3 / 2}^{0}$ & 5463.85 & 1.47 & 0.83 \\
\hline $6 \mathrm{p}^{2} \mathrm{Po}_{1 / 2}-6 \mathrm{~d}^{2} \mathrm{D}_{3 / 2}$ & 3577.13 & 1.13 & 1.61 \\
\hline $6 \mathrm{p}^{2} \mathrm{P}^{\mathrm{o}}{ }_{3 / 2}-6 \mathrm{~d}^{2} \mathrm{D}_{3 / 2}$ & 3795.07 & 1.27 & 1.57 \\
\hline $6 \mathrm{p}^{2} \mathrm{P}^{\mathrm{o}}{ }_{3 / 2}-6 \mathrm{~d}^{2} \mathrm{D}_{5 / 2}$ & 3687.95 & 1.20 & 1.59 \\
\hline $6 \mathrm{~d}^{2} \mathrm{D}_{3 / 2}-6 \mathrm{f}^{2} \mathrm{~F}^{\mathrm{O}}{ }_{5 / 2}$ & 3751.67 & 2.80 & 3.74 \\
\hline $6 \mathrm{~d}^{2} \mathrm{D}_{5 / 2}-6 \mathrm{f}^{2} \mathrm{~F}^{\mathrm{O}}{ }_{5 / 2}$ & 3775.08 & 2.83 & 3.74 \\
\hline $6 \mathrm{~d}^{2} \mathrm{D}_{5 / 2}-6 \mathrm{f}^{2} \mathrm{~F}^{\mathrm{o}}{ }_{7 / 2}$ & 3765.39 & 2.82 & 3.77 \\
\hline
\end{tabular}

Table 2. Estimated Stark widths for 18 spectral lines of Zr IV according to Purić and Šćepanović, 1999 (W $\left.\mathrm{W}_{\mathrm{PS} 99}\right)$ and Purić et al., $1991\left(\mathrm{~W}_{\mathrm{P} 91}\right)$ for a temperature of $\mathrm{T}=10,000 \mathrm{~K}$ and electron density of $\mathrm{N}=10^{23} \mathrm{~m}^{-3}$. Estimated Stark widths are compared with MSE calculated Stark widths $\mathrm{W}_{\text {MSE }}[5]$.

\begin{tabular}{|c|c|c|c|c|c|}
\hline Transition & $\lambda(\AA)$ & W $_{\text {PS99 }}(\AA ̊)$ & $W_{P 91}(\AA)$ & $\mathrm{W}_{\text {PS99 }} / \mathrm{W}_{\text {MSE }}$ & $\mathbf{W}_{\mathrm{P} 91} / \mathrm{W}_{\mathrm{MSE}}$ \\
\hline $5 s^{2} S_{1 / 2}-5 p^{2} P_{1 / 2}^{o}$ & 2287.38 & 0.118 & 0.0530 & 1.40 & 0.63 \\
\hline $5 s^{2} S_{1 / 2}-5 p^{2} P_{3 / 2}^{o}$ & 2164.36 & 0.110 & 0.0530 & 1.40 & 0.63 \\
\hline $5 s^{2} \mathrm{~S}_{1 / 2}-6 \mathrm{p}^{2} \mathrm{P}_{1 / 2}^{\mathrm{O}}$ & 760.16 & 0.0826 & 0.0164 & 8.34 & 1.66 \\
\hline $5 s^{2} S_{1 / 2}-6 p^{2} P_{3 / 2}^{o}$ & 754.39 & 0.0837 & 0.0164 & 8.21 & 1.61 \\
\hline $5 \mathrm{p}^{2} \mathrm{P}_{1 / 2}^{\mathrm{o}}-5 \mathrm{~d}^{2} \mathrm{D}_{3 / 2}$ & 1546.17 & 0.187 & 0.0485 & 4.43 & 1.15 \\
\hline $5 \mathrm{p}^{2} \mathrm{P}_{3 / 2}^{\mathrm{o}}-5 \mathrm{~d}^{2} \mathrm{D}_{3 / 2}$ & 1607.95 & 0.202 & 0.0525 & 4.31 & 1.12 \\
\hline $5 \mathrm{p}^{2} \mathrm{P}_{3 / 2}^{\mathrm{o}}-5 \mathrm{~d}^{2} \mathrm{D}_{5 / 2}$ & 1598.95 & 0.201 & 0.0521 & 4.34 & 1.13 \\
\hline $5 \mathrm{~d}^{2} \mathrm{D}_{3 / 2}-5 \mathrm{f}^{2} \mathrm{~F}^{\mathrm{o}}{ }_{5 / 2}$ & 1836.10 & 1.39 & 0.173 & 17.03 & 2.13 \\
\hline $5 d^{2} D_{5 / 2}-5 f^{2} F^{0}{ }_{5 / 2}$ & 1848.03 & 1.41 & 0.176 & 17.05 & 2.12 \\
\hline $5 d^{2} D_{5 / 2}-5 f^{2} F^{o}{ }_{7 / 2}$ & 1846.37 & 1.41 & 0.176 & 17.09 & 2.13 \\
\hline $6 s^{2} S_{1 / 2}-6 p^{2} P_{1 / 2}{ }^{o}$ & 5781.45 & 4.77 & 0.950 & 2.42 & 0.48 \\
\hline $6 s^{2} \mathrm{~S}_{1 / 2}-6 \mathrm{p}^{2} \mathrm{P}_{3 / 2}^{\mathrm{o}}$ & 5463.85 & 4.39 & 0.862 & 2.47 & 0.48 \\
\hline $6 \mathrm{p}^{2} \mathrm{P}^{\mathrm{o}}{ }_{1 / 2}-6 \mathrm{~d}^{2} \mathrm{D}_{3 / 2}$ & 3577.13 & 4.64 & 0.611 & 6.61 & 0.87 \\
\hline $6 \mathrm{p}^{2} \mathrm{P}^{\mathrm{o}}{ }_{3 / 2}-6 \mathrm{~d}^{2} \mathrm{D}_{3 / 2}$ & 3795.07 & 5.22 & 0.688 & 6.44 & 0.85 \\
\hline $6 \mathrm{p}^{2} \mathrm{P}_{3 / 2}^{\mathrm{o}}-6 \mathrm{~d}^{2} \mathrm{D}_{5 / 2}$ & 3687.95 & 4.96 & 0.652 & 6.56 & 0.86 \\
\hline $6 \mathrm{~d}^{2} \mathrm{D}_{3 / 2}-6 \mathrm{f}^{2} \mathrm{~F}^{\mathrm{o}}{ }_{5 / 2}$ & 3751.67 & 18.0 & 1.36 & 24.10 & 1.82 \\
\hline $6 d^{2} D_{5 / 2}-6 f^{2} F^{o}{ }_{5 / 2}$ & 3775.08 & 18.2 & 1.37 & 24.04 & 1.82 \\
\hline $6 \mathrm{~d}^{2} \mathrm{D}_{5 / 2}-6 \mathrm{f}^{2} \mathrm{~F}^{\mathrm{o}}{ }_{7 / 2}$ & 3765.39 & 18.2 & 1.37 & 24.27 & 1.83 \\
\hline
\end{tabular}

Additionally, following Purić's approach, we tried without success to represent our MSE widths for Zr IV, in angular frequency units, as a polynomial of upper effective principal quantum number or to obtain a linear dependence between them in log-log scale with correlation coefficient above $90 \%$ (which proves that the dependence is reliable). However, the correlation coefficient for log-log regression with lower $n^{*}$ is around $88 \%$ :

$$
\mathrm{W}_{\mathrm{E} 3}=1.37 \times 10^{-9} \lambda^{2} n_{\text {lower }}^{*}{ }^{2.47}
$$


(in this case, $\mathrm{W}_{\mathrm{MSE}}$ can be estimated as $\mathrm{W}_{\mathrm{MSE}}=1.54 \AA \times \mathrm{W}_{\mathrm{E} 3}-0.14$ with correlation coefficient of around $93 \%$ ) against, for example, around $60 \%$ for upper $n^{*}$. But we found the polynomial dependence between Stark widths and the corresponding spectral line wavelengths instead, in a form:

$$
\mathrm{W}_{\mathrm{E} 4}=C_{4} \lambda^{4}+C_{3} \lambda^{3}+C_{2} \lambda^{2}+C_{1} \lambda+C_{0}
$$

where $C_{4}=-0.6 \times 10^{-14}, C_{3}=0.63 \times 10^{-10}, C_{2}=-0.12 \times 10^{-6}, C_{1}=0.7 \times 10^{-4}$ and $C_{0}=0.44 \times 10^{-2}$ [5]. Correlation coefficient for this polynomial regression of $4^{\text {th }}$ degree is $99.9 \%$. In all of those estimations parameters are obtained for condition of $\mathrm{T}=10,000 \mathrm{~K}$ and $\mathrm{N}=10^{23} \mathrm{~m}^{-3}$.

Unfortunately there is no experimental data for $\mathrm{Zr}$ IV. A comparison of our results with reliable experimental data will be of interest so we encourage such measurements.

Table 3. Ranges of values of ratios of $W_{\mathrm{COW}}, \mathrm{W}_{\mathrm{PS} 99}$ and $\mathrm{W}_{\mathrm{P} 91}$ with $\mathrm{W}_{\mathrm{MSE}}$ for different types of transitions.

\begin{tabular}{cccc}
\hline Transition & $\mathbf{W}_{\text {COW }} / \mathbf{W}_{\text {MSE }}$ & W $_{\text {PS99 }} / \mathbf{W}_{\text {MSE }}$ & W $_{\text {P91 }} / \mathbf{W}_{\text {MSE }}$ \\
\hline s-p & $0.82-2.82$ & $1.40-8.34$ & $0.48-1.66$ \\
p-d & $1.57-1.86$ & $4.43-6.61$ & $0.85-1.15$ \\
d-f & $3.74-3.97$ & $17.03-24.27$ & $1.82-2.13$ \\
\hline
\end{tabular}

\section{Conclusions}

We tested Cowley's [7] formula and several expressions for quick calculation of electron-impact widths on the basis of regularity and systematic trends, comparing them with MSE results of $\mathrm{Zr}$ IV spectral lines calculated elsewhere Majlinger et al. [5]. We demonstrated that Cowley's formula increasingly overestimate Stark width, obtained by using the modified semiempirical method, with the increase of angular momentum quantum number because of its neglection in the Cowley's approach. It is also found that the results obtained by using formula for simple estimates of Puric et al. (1991) are in agreement with the modified semiempirical results within the estimated error bars of both methods, while the estimates using formula of Purić and Šćepanović (1999) are in strong disagreement which increases with the increase of angular orbital momentum quantum number.

Acknowledgments: The support of Ministry of Education, Science and Technological Development of Republic of Serbia through project 176002 is gratefully acknowledged.

Author Contributions: These authors contributed equally to this work.

Conflicts of Interest: The authors declare no conflict of interest. The founding sponsors had no role in the design of the study; in the collection, analyses, or interpretation of data; in the writing of the manuscript, and in the decision to publish the results.

\section{References}

1. Sahal-Bréchot, S.; Dimitrijević, M.S.; Moreau, N.; Ben Nessib, N. The Stark-B database VAMDC node for spectral line broadening by collisions with charged particles. In SF2A-2014, Proceedings of the Annual Meeting of the French Society of Astronomy and Astrophysics, Paris, France, 3-6 June 2014; Ballet, J., Bournaud, F., Martins, F., Monier, R., Reyle, C., Eds.; French Society of Astronomy \& Astrophysics (SF2A): Paris, France, 2014; pp. 515-521.

2. Sahal-Bréchot, S.; Dimitrijević, M.S.; Moreau, N.; Ben Nessib, N. The STARK-B database VAMDC node: A repository for spectral line broadening and shifts due to collisions with charged particles. Phys. Scr. 2015, 90, 054008.

3. Sahal-Bréchot, S.; Dimitrijević, M.S.; Moreau, N. STARK-B Database, Observatory of Paris, LERMA and Astronomical Observatory of Belgrade. 2017. Available online: http://stark-b.obspm.fr (accessed on 24 August 2017).

4. Wiese, W.L.; Konjević, N. Regularities and similarities in plasma broadened spectral line widths (Stark widths). J. Quant. Spectrosc. Radiat. Transf. 1982, 28, 185-198. 
5. Majlinger, Z.; Simić, Z.; Dimitrijević, M.S. Stark broadening of Zr iv spectral lines in the atmospheres of chemically peculiar stars. Mon. Not. R. Astron. Soc. 2017, 470, 1911-1918.

6. Dimitrijević, M.S.; Konjević, N. Stark widths of doubly- and triply-ionized atom lines. J. Quant. Spectrosc. Radiat. Transf. 1980, 24, 451-459.

7. Cowley, C.R. An approximate Stark broadening formula for use in spectrum synthesis. Observatory 1971, 91, 139-140.

8. Purić, J.; Ćuk, M.; Dimitrijević, M.S.; Lessage, A. Regularities of Stark parameters along the periodic table. Astrophys. J. 1991, 382, 353-357.

9. Purić, J.; Šćepanović, M. General Regularities of Stark Parameters for Ion Lines. Astrophys. J. 1999, 521, 490-491.

10. Griem, H.R. Semiempirical Formulas for the Electron-Impact Widths and Shifts of Isolated Ion Lines in Plasmas. Phys. Rev. 1968, 165, 258-266.

11. Killian, J.; Montenbruck, O.; Nissen, P.E. Chemical abundances in early B-type stars. II-Line identification and atomic data for high resolution spectra. Astron. Astrophys. 1991, 88, 101-119.

12. Ziegler, M.; Rauch, T.; Werner, K.; Köpen, J.; Kruk, J.W. BD $22^{\circ} 3467$, a DAO type star exciting the nebula Abell 35. Astron. Astrophys. 2012, 548, A109.

13. Przybilla, N.; Fossati, L.; Hubrig, S.; Nieva, M.-F.; Järvinen, S.P.; Castro, N.; Schöller, M.; Ilyin, I.; Butler, K.; Schneider, F.R.N.; et al. B fields in OB stars (BOB): Detection of a magnetic field in the He-strong star CPD 573509. Astron. Astrophys. 2016, 587, A7.

14. Majlinger, Z.; Simić, Z.; Dimitrijević, M.S. On the Stark Broadening of Lu III Spectral Lines. J. Astrophys. Astron. 2015, 36, 671-679.

15. Peláez, R.J.; Djurović, S.; Ćirišan, M.; Aparacio, J.A.; Mar, S. Stark halfwidth trends along the homologous sequence of singly ionized noble gases. Astron. Astrophys. 2010, 518, A60.

16. Elabidi, H.; Sahal-Bréchotot, S. Checking the dependence on the upper level ionization potential of electron impact widths using quantum calculations. Eur. Phys. J. D 2011, 61, 285-290.

17. Hamdi, R.; Ben Nessib, N.; Dimitrijević, M.S.; Sahal-Bréchot, S. Stark broadening of spectral lines of Pb IV. Mon. Not. R. Astron. Soc. 2013, 431, 1039-1047.

(C) 2017 by the authors. Licensee MDPI, Basel, Switzerland. This article is an open access article distributed under the terms and conditions of the Creative Commons Attribution (CC BY) license (http://creativecommons.org/licenses/by/4.0/). 